\title{
Fatal cerebral edema associated with serine deficiency in CSF
}

\author{
Irene M. L. W. Keularts • Piet L. J. M. Leroy • Estela M. Rubio-Gozalbo • \\ Leo J. M. Spaapen • Biene Weber • Bert Dorland • Tom J. de Koning • \\ Nanda M. Verhoeven-Duif
}

Received: 11 November 2009 /Revised: 4 February 2010 / Accepted: 9 February 2010 /Published online: 19 March 2010

(C) The Author(s) 2010. This article is published with open access at Springerlink.com

\begin{abstract}
Two young girls without a notable medical history except for asthma presented with an acute toxic encephalopathy with very low serine concentrations both in plasma and cerebrospinal fluid (CSF) comparable to patients with 3-phosphoglycerate dehydrogenase (3-PGDH) deficiency. Clinical symptoms and enzyme measurement (in one patient) excluded 3-PGDH deficiency. Deficiencies in other serine biosynthesis enzymes were highly unlikely on clinical grounds. On basis of the fasting state, ketone bodies and lactate in plasma, urine and CSF, we speculate
\end{abstract}

Communicated by: Jaak Jaeken

Competing interest: None declared.

I. M. L. W. Keularts $(\bowtie) \cdot$ E. M. Rubio-Gozalbo •

L. J. M. Spaapen $\cdot$ B. Dorland

Laboratory for Biochemical Genetics, Dept. Clinical Genetics,

Maastricht University Medical Center,

P. Debyelaan 25,

6229 HXMaastricht, The Netherlands

e-mail: irene.keularts@mumc.nl

\section{P. L. J. M. Leroy • E. M. Rubio-Gozalbo}

Department of Pediatrics, Maastricht University Medical Center,

Maastricht, The Netherlands

B. Weber

Department of Neurology, Maastricht University Medical Center,

Maastricht, The Netherlands

\section{T. J. de Koning}

Department of Pediatrics, Wilhelmina Children's Hospital, University Medical Center Utrecht,

Utrecht, Netherlands

\section{N. M. Verhoeven-Duif}

Department of Metabolic and Endocrine Diseases, and Netherlands Metabolomics Center,

University Medical Center Utrecht,

Utrecht, The Netherlands that reduced serine levels were due to its use as gluconeogenic substrate, conversion to pyruvate by brain serine racemase or decreased L-serine production because of a lack of glucose. These are the first strikingly similar cases of patients with a clear secondary serine deficiency associated with a toxic encephalopathy.

\section{Introduction}

L-Serine, a nonessential amino acid, plays an important role in cellular proliferation (Snell 1984). In addition, L-serine is the precursor of the neurotransmitters D-serine and glycine and is involved in one-carbon metabolism. L-Serine can be derived from different sources, such as dietary intake, degradation of proteins and phospholipids, and glucose via the glycolytic intermediates 3-phosphoglycerate and 3phosphohydroxypyruvate (de Koning et al. 2003).

Three enzymes are involved in serine biosynthesis: 3-phosphoglycerate dehydrogenase (3-PGDH), 3phosphohydroxypyruvate aminotransferase, and phosphoserine phosphatase. Genetic 3-PGDH deficiency (Jaeken et al. 1996; de Koning et al. 2000) is associated with congenital microcephaly, severe psychomotor retardation, and intractable seizures (de Koning et al. 2004). The biochemical hallmark of this disorder is a significantly reduced concentration of $\mathrm{L}$-serine and, to a variable degree, glycine, in cerebrospinal fluid (CSF) and plasma (de Koning et al. 2000). Deficiencies of the other two enzymes involved in the L-serine biosynthesis show clinical phenotypes (severe neurological symptoms, severe psychomotor retardation, and seizures) similar to that found in 3-PGDH deficiency (Hart et al. 2007; Jaeken et al. 1997; Veiga-daCunha et al. 2004). Decreased serine in CSF has also been described in cases in which the biochemical defect 
Table 1 Summary of cerebral spinal fluid (CSF) and plasma amino acids in the two patients dying from brain-stem compression after acute cerebral edema

\begin{tabular}{|c|c|c|c|c|c|c|c|}
\hline \multirow[t]{2}{*}{ Amino acid } & & \multicolumn{3}{|l|}{ Measurement } & \multicolumn{3}{|c|}{ Reference values } \\
\hline & & $\mathrm{CSF}(\mu \mathrm{mol} / \mathrm{l})$ & Plasma & Ratio & $\mathrm{CSF}(\mu \mathrm{mol} / \mathrm{l})$ & Plasma & Ratio \\
\hline Serine & $\begin{array}{l}\text { Patient } 1 \\
\text { Patient } 2\end{array}$ & $\begin{array}{l}8 \\
7\end{array}$ & $\begin{array}{l}31 \\
33\end{array}$ & $\begin{array}{l}0.258 \\
0.242\end{array}$ & $19-38$ & $95-166$ & $0.276 \pm 0.053$ \\
\hline \multicolumn{2}{|c|}{ Serine (3-PGDH def) ${ }^{a}$} & $6-8$ & \multicolumn{2}{|l|}{$28-64$} & & & \\
\hline Glycine & $\begin{array}{l}\text { Patient } 1 \\
\text { Patient } 2\end{array}$ & $\begin{array}{l}5 \\
6\end{array}$ & $\begin{array}{l}107 \\
185\end{array}$ & $\begin{array}{l}0.047 \\
0.032\end{array}$ & $0.7-15$ & $139-317$ & $<0.0400$ \\
\hline \multicolumn{2}{|c|}{ Glycine (3-PGDH def) ${ }^{a}$} & $1-4$ & \multicolumn{2}{|l|}{ 128-190 } & & & \\
\hline Threonine & $\begin{array}{l}\text { Patient } 1 \\
\text { Patient } 2\end{array}$ & $\begin{array}{l}17 \\
11\end{array}$ & $\begin{array}{l}61 \\
29\end{array}$ & $\begin{array}{l}0.279 \\
0.379\end{array}$ & $22-47$ & $49-183$ & $0.291 \pm 0.053$ \\
\hline Alanine & $\begin{array}{l}\text { Patient } 1 \\
\text { Patient } 2\end{array}$ & $\begin{array}{l}14 \\
37\end{array}$ & $\begin{array}{l}72 \\
181\end{array}$ & $\begin{array}{l}0.194 \\
0.204\end{array}$ & $8-42$ & $153-560$ & $0.112 \pm 0.028$ \\
\hline
\end{tabular}

$C S F$ cerebral spinal fluid, 3-PGDH 3-phosphohydroxypyruvate aminotransferase

${ }^{\text {a }}$ de Koning et al. 2004

remained unsolved. One of these patients showed growth retardation, progressive polyneuropathy, and ichthyosis; supplementation with L-serine produced clinical improvement (Catsman-Berrevoets et al. 1997).

Here we describe two patients with severe encephalopathy associated with a viral infection and serine deficiency in plasma and CSF. In the medical histories, asthma is the only notable clinical condition. Possible mechanisms for the extremely low serine concentrations in CSF are discussed.

\section{Patient 1}

A 7-year old, normally developing girl was diagnosed with moderately severe asthma for which she used inhalation therapy with combination of salmeterol/fluticasone. The day before her death, she presented with a mild febrile condition, including malaise, headache, and nausea. Medical examination showed no abnormality, and domperidone was prescribed. The morning before her death, her mother found her unresponsive in bed, probably following a seizure. At that time, blood glucose, as measured by a bed-side apparatus, was $2.1 \mathrm{mmol} / \mathrm{l}$. In the emergency room, the patient had convulsions, which responded to diazepam. Physical examination showed expiratory wheezing, normal blood pressure and capillary refill time, a relatively low heart rate $(100 / \mathrm{min})$, no hepatosplenomegaly, normal pupils, and no signs of trauma or bleeding. Hypoglycemia or electrolyte disturbances were excluded. Liver enzymes and bilirubin were slightly elevated, and blood ammonia was normal $(15 \mu \mathrm{mol} / \mathrm{l})$. She regained consciousness for $1.5 \mathrm{~h}$ but became progressively dyspneic and presented suddenly with apnea and desaturation, decortication rigidity, bilateral fixed mydriatic pupils, and deep coma. She was intubated and treated with dexamethasone and mannitol. A brain computed tomography (CT) scan showed bilateral central herniation and cerebral edema. There were indisputable signs of brain death, and she died $24 \mathrm{~h}$ after the first symptoms.

Amino acid analysis of both plasma and CSF revealed strongly decreased serine concentrations (Tables 1, 2, 3)

Table 2 Plasma concentrations of all amino acids ( $\mu \mathrm{mol} / \mathrm{l})$ in the two patients

\begin{tabular}{llll}
\hline Amino acid & Patient 1 & Patient 2 & Reference values \\
\hline Taurine & 21 & 72 & $9-130$ \\
Threonine & 61 & 29 & $49-183$ \\
Serine & $\mathbf{3 1}$ & $\mathbf{3 3}$ & $\mathbf{9 5 - 1 6 6}$ \\
Asparagine & 18 & 6 & $18-69$ \\
Glutamic acid & 23 & 28 & $1-105$ \\
Glutamine & 301 & 262 & $317-757$ \\
Proline & 70 & 149 & $26-412$ \\
Glycine & 107 & 185 & $139-317$ \\
Alanine & 72 & 181 & $153-560$ \\
Citrulline & 15 & 4 & $10-57$ \\
Valine & 158 & 73 & $120-323$ \\
Cystine & 6 & 18 & $0-42$ \\
Methionine & 9 & 7 & $13-38$ \\
Isoleucine & 59 & 13 & $24-100$ \\
Leucine & 120 & 48 & $49-179$ \\
Tyrosine & 36 & 43 & $30-109$ \\
Phenylalanine & 70 & 46 & $28-92$ \\
Ornithine & 34 & 12 & $30-96$ \\
Lysine & 96 & 47 & $81-217$ \\
Histidine & 89 & 47 & $55-104$ \\
Arginine & 38 & 31 & $29-124$ \\
\hline
\end{tabular}


Table 3 CSF concentrations of all amino acids $(\mu \mathrm{mol} / \mathrm{l})$ in the two patients

\begin{tabular}{llll}
\hline Amino acid & Patient 1 & Patient 2 & Reference values \\
\hline Taurine & 10 & 4 & $2-12$ \\
Threonine & 1 & 11 & $22-47$ \\
Serine & $\mathbf{8}$ & 7 & $\mathbf{1 9 - 3 8}$ \\
Asparagine & 4 & 6 & $2-17$ \\
Glutamic acid & & 1 & $0-16$ \\
Glutamine & 380 & 357 & $234-689$ \\
Proline & 1 & 0 & $0-2$ \\
Glycine & 5 & 6 & $1-15$ \\
Alanine & 14 & 37 & $8-42$ \\
Citrulline & 3 & 1 & $0-3$ \\
Valine & 15 & 17 & $8-24$ \\
Cystine & 1 & 4 & $0-2$ \\
Methionine & 3 & 5 & $0-7$ \\
Isoleucine & 5 & 0 & $2-11$ \\
Leucine & 18 & 9 & $6-21$ \\
Tyrosine & 2 & 6 & $0-25$ \\
Phenylalanine & 28 & 24 & $6-19$ \\
Ornithine & 43 & 4 & $1-9$ \\
Lysine & 31 & 13 & $8-35$ \\
Histidine & 32 & 21 & $4-23$ \\
Arginine & 20 & 5 & $4-35$ \\
\hline
\end{tabular}

comparable with levels observed in patients with 3-PGDH deficiency (de Koning et al. 2004). Enantiomer separation revealed D-serine to be $0.9 \mu \mathrm{mol} / \mathrm{L}$ (ref. $0.8-4.3 \mu \mathrm{mol} / \mathrm{L}$ ) and L-serine $4.0 \mu \mathrm{mol} / \mathrm{L}$ (ref. 17.2-44.0 $\mu \mathrm{mol} / \mathrm{L}$ ), with slightly elevated D-serine/total serine ratio of $18 \%$ in CSF (Fuchs et al. 2006). Concentrations of the other amino acids were normal or decreased according to a nonspecific pattern (data not shown). A deficiency of 3-phosphoglycerate dehydrogenase was excluded in cultured fibroblasts (43 nmol/mg per min; normal $29.5 \pm 2.7 \mathrm{nmol} / \mathrm{mg}$ per min). Further metabolic screening revealed increased ketone bodies and lactate in urine, plasma, and CSF (Table 4). Plasma acylcarnitine profile showed an elevated concentration of $\mathrm{OH}-\mathrm{C} 4-$ carnitine. A fatty acid oxidation defect was excluded. Brain microscopy showed bilateral necrosis in the cerebral tonsils compatible with central herniation. No signs of encephalitis or meningitis were found, but diffuse interstitial edema was obviously present. Postmortem microbiology sampling yielded a parainfluenza type II virus in the lungs, probably explaining fever onset and asthmatic signs as her presenting condition. The clinical picture probably reflects a toxic encephalopathy.

\section{Patient 2}

A 4-year-old girl with normal mental development suffered from asthma for which she used Flixotide (a steroid, $2 \mathrm{dd} 250 \mu \mathrm{g})$ and salmeterol $(2 \mathrm{dd} 25 \mu \mathrm{g})$. She had normal height but severe malnutrition [weight $<2$ standard deviations (SD)] due to feeding difficulties related to behavioral problems. Because of sleep disturbances, the patient had been on treatment with Alimemazine (an antihistaminic sedative agent) for 4 months. Two days before her death (in the evening, day $1)$, she presented with fever $\left(39-40^{\circ} \mathrm{C}\right)$ without other particularities. The next morning (day 2), she was found in bed with tonic clonic seizures. The seizures were resistant to multiple anticonvulsive drugs. There were no signs of respiratory or circulatory failure. On admission, serum glucose was $4.0 \mathrm{mmol} / \mathrm{L}$, with CSF glucose $1.0 \mathrm{mmol} / \mathrm{L}$; serum electrolytes were normal, as was blood ammonia $(15 \mu \mathrm{mol} / \mathrm{l})$. There were no signs of a bacterial central nervous system (CNS) infection in CSF, no pleocytosis, and bacterial and viral cultures remained negative; later nasal cultures, however, showed an adenovirus V. Blood C-reactive protein (CRP) was $>300 \mathrm{mg} / \mathrm{ml}$.

Physical examination showed a very ill girl with coma scores E1, M4, V1. Intubation and cardiac support were effective for some hours, but a rapid deterioration was seen with an isoelectric electroencephalogram (EEG) pattern and absent stem reflexes. After a repeated isoelectric EEG, the next day, supportive treatment was discontinued. No postmortem examination was performed. Metabolic investigations in plasma and CSF taken at day 2 showed particularly low plasma and CSF serine concentrations. Concentrations of the other amino acids were normal or decreased according to a nonspecific pattern (data not

Table 4 Plasma, urine and CSF concentrations of lactate and ketone bodies in the two patients with an acute encephalopathy

\begin{tabular}{llllll}
\hline Patient & $\begin{array}{l}\text { Urine lactate } \\
(\mu \mathrm{mol} / \mathrm{mmol} \text { creat })\end{array}$ & $\begin{array}{l}\text { Urine 3-OHB } \\
(\mu \mathrm{mol} / \mathrm{mmol} \text { creat })\end{array}$ & $\begin{array}{l}\text { CSF lactate } \\
(\mu \mathrm{mol} / \mathrm{l})\end{array}$ & $\begin{array}{l}\text { CSF 3-OHB } \\
(\mu \mathrm{mol} / \mathrm{l})\end{array}$ \\
\hline Patient 1 & $374(<56)$ & $22410(<5)$ & $2308(<1700)$ & $1731(<280)$ & $\begin{array}{l}\text { Plasma 3-OHB } \\
(\mu \mathrm{mol} / \mathrm{l})\end{array}$ \\
Patient 2 & $130(<56)$ & $317(<5)$ & $7200(<1700)$ & n.d. & $2200(<5)$ \\
\hline
\end{tabular}

nd, not determined

Urine and plasma from patient 1 were collected the day before death. 
shown). Unfortunately, no fibroblasts were available for analysis of 3-PGDH activity. Plasma lactate and 3hydroxybutyrate were clearly increased, as was CSF lactate (Table 4). Urine organic acid analysis showed a moderate ketonuria as well as a marginally elevated lactate excretion.

\section{Discussion}

Here we present two young female patients with extremely low serine concentrations in CSF and plasma comparable with 3-PGDH-deficient patients without clinical features suggestive for a serine biosynthesis defect. Both patients showed a rapidly progressive toxic encephalopathy and brain edema causing death within $24 \mathrm{~h}$ after the first symptoms. Acute toxic encephalopathy has been described in young children (2-3 years of age) without a notable medical history (de Jong-de Vos van Steenwijk et al. 1981), with cerebral edema and fatal brain-stem compression as the major cause of death. Possible triggers include infections by several bacteria or viruses. Our patients suffered from parainfluenza virus type II (patient 1) and a nasal adenovirus 5 (patient 2), respectively. Both viruses have been associated with acute encephalopathy (Hata et al. 2007; Straussberg et al. 2001). The pathogenesis of acute toxic encephalopathy has not been elucidated. Toxins leading to either endothelial cell damage with disruption of the blood-brain barrier (Ashkenazi et al. 1990) or directly affecting cells leading to cytotoxic edema (Kimelberg 1995) might play a role. A relationship between acute encephalopathy and low CSF serine concentration has never been reported.

Both our patients had an overnight (fasting) period before serious neurological symptoms occurred. Low plasma concentrations of (essential) amino acids and increased ketone bodies in urine and plasma reflected this fasting state. In addition, plasma alanine concentrations of $72 \mu \mathrm{M}$ and $181 \mu \mathrm{M}$ made a gluconeogenesis defect unlikely. In cases of fasting in combination with fever/illness, a cerebral hypoglycemic state could trigger formation of ketone bodies as an alternative source of energy for the brain. In patient 1 , we confirmed an increased concentration of 3-OH-butyrate in CSF. In patient 2, the low CSF glucose concentration relative to plasma concentration might suggest a glucose transporter 1 (GLUT-1) defect (MIM\# 606777) despite the absence of clinical symptoms of this genetic defect (Wang et al. 2005); CSF glucose concentration, however, normalized upon glucose bolus.

In addition to ketone bodies, L-serine is a potential energy source under certain conditions in cerebral tissue. L-serine does not easily cross the blood-brain barrier, and glial cells contain enzymes of the complete serine synthesis and degradation pathways (Furuya and Watanabe 2003; Mitoma et al. 1998). Serine racemase, present in different regions of the brain (de Miranda et al. 2000), can synthesize D-serine, as well as pyruvate, from L-serine (de Miranda et al. 2002; Wolosker et al. 2002). The formed pyruvate may act as a local, emergency energy substrate (Wu et al. 2004). In both patients with a clear cerebral emergency situation, L-serine might have been used as an alternative energy source. The relatively high percentage of D-serine ( $18 \%$ of total serine, ref. 3-16\%) (Fuchs et al. 2006) supports this possibility.

In order to study the role of L-serine in energy metabolism in the hypoglycemic brain, we analyzed CSF of four patients diagnosed with a GLUT-1 deficiency. No changes in amino acids in CSF from these patients were observed (results not published). From this observation, we conclude that a chronic low CSF glucose concentration, as present in GLUT-1-deficient patients, does not explain the low CSF serine concentration. An alternative explanation for the low CSF serine concentration is a decreased production of serine from glucose due to an acute hypoglycemic state. The low concentration of plasma Lserine, as observed in our patients, is in line with this idea. In general, fasting patients show mildly decreased plasma and CSF serine concentrations (M. Duran, Amsterdam, personal communication), which are, however, not as low as those observed in our patients. These observations indicate that it is probably the extreme local energy deficit that might contribute to a low cerebral serine concentration. In addition to hypoglycemia, an increased nicotinamide adenine dinucleotide, reduced nicotinamide adenine dinucleotide $\left(\mathrm{NADH} / \mathrm{NAD}^{+}\right.$) ratio as seen in anoxia might be considered as a cause of inhibition of serine synthesis. However, we observed increased concentrations of CSF Lserine (threefold) and glycine (tenfold) in patients with asphyxia compared with controls (data not published).

In summary, we observed low serine concentrations in two young girls who died from cerebral edema with brainstem compression. The low serine concentrations were not caused by an inherited disorder of metabolism but probably reflected a pathophysiological state of the brain in which L-serine was either used to produce pyruvate via serine racemase, or Lserine production failed due to a lack of glucose.

Acknowledgement We thank Prof. Dr. R.J.A. Wanders (AMC, Amsterdam) for the measurement of palmitate and oleate oxidation in fibroblasts in patient 1

Competing interest None declared

Open Access This article is distributed under the terms of the Creative Commons Attribution Noncommercial License which permits any noncommercial use, distribution, and reproduction in any medium, provided the original author(s) and source are credited. 


\section{References}

Ashkenazi S, Cleary KR, Pickering LK, Murray BE et al (1990) The association of shiga toxin and other cytotoxins with the neurologic manifestations of shigellosis. J Infect Dis 161:961-965

Catsman-Berrevoets CE, de Klerk JBC, Huijmans JGM, Duran M (1997) Inborn error of serine biosynthesis, a new phenotype. Eur J Paediat Neurol 1:A43

de Jong-de Vos van Steenwijk CCE, Van Nieuwenhuizen O, van Vught AJ (1981) Toxische encefalopathie bij een infectieziekte op de kinderleeftijd. Ned Tijdschr Geneeskd 125:1557-1560

de Koning TJ, Klomp LW (2004) Serine-deficiency syndromes. Curr Opin Neurol 17(2):197-204

de Koning TJ, Jaeken J, Pineda M, Van Maldergem L et al (2000) Hypomyelination and reversible white matter attenuation in 3phosphoglycerate dehydrogenase deficiency. Neuropediatrics 31:287-292

de Koning TJ, Snell K, Duran M, Berger R et al (2003) L-serine in disease and development. Biochem J 371:653-661

de Koning TJ, Klomp LW, Van Oppen AC, Beemer FA et al (2004) Prenatal and early postnatal treatment in 3-phosphoglyceratedehydrogenase deficiency. Lancet 364:2221-2222

de Miranda J, Santoro A, Engelender S, Wolosker H (2000) Human serine racemase: molecular cloning, genomic organization and functional analysis. Gene 256:183-188

de Miranda J, Panizzutti R, Foltyn VN, Wolosker H (2002) Cofactors of serine racemase that physiologically stimulate the synthesis of the $N$-methyl-D-aspartate (NMDA) receptor coagonist D-serine. Proc Natl Acad Sci USA 99:14527-14542

Fuchs SA, Dorland L, de Sain-Van der Velden MG, Hendriks M et al (2006) D-serine in the developing human central nervous system. Ann Neurol 60:476-480

Furuya S, Watanabe M (2003) Novel neuroglial and glioglial relationships mediated by L-serine metabolism. Arch Histol Cytol 66:109-121
Hart CE, Race V, Achouri Y, Wiame E et al (2007) Phosphoserine aminotransferase deficiency: a novel disorder of the serine biosynthesis pathway. Am J Hum Genet 80(5):931-937

Hata M, Ito M, Kiyosawa S, Kimpara Y et al (2007) A fatal case of encephalopathy possibly associated with human metapneumovirus infection. Jpn J Infect Dis 60(5):328-329

Jaeken J, Detheux M, Van Maldergem L, Foulon M et al (1996) 3Phosphoglycerate dehydrogenase deficiency: an inborn error of serine biosynthesis. Arch Dis Child 74:542-545

Jaeken J, Detheux M, Fryns JP, Collet JF et al (1997) Phosphoserine phosphatase deficiency in a patient with Williams syndrome. J Med Genet 34(7):594-596

Kimelberg HK (1995) Current concepts of brain edema. Review of laboratory investigations. J Neurosurg 83:1051-1059

Mitoma J, Furuya S, Hirabayashi Y (1998) A novel metabolic communication between neurons and astrocytes: non-essential amino acid L-serine released from astrocytes is essential for developing hippocampal neurons. Neurosci Res 30:195-199

Snell K (1984) Enzymes of serine metabolism in normal, developing and neoplastic rat tissues. Adv Enzyme Regul 22:325-400

Straussberg R, Harel L, Levy Y, Amir J (2001) A syndrome of transient encephalopathy associated with adenovirus infection. Pediatrics 107:E69

Veiga-da-Cunha M, Collet JF, Prieur B, Jaeken J et al (2004) Mutations responsible for 3-phosphoserine phosphatase deficiency. Eur J Hum Genet 12(2):163-166

Wang D, Pascual JM, Yang H, Engelstad K (2005) Glut-1 deficiency syndrome: clinical, genetic, and therapeutic aspects. Ann Neurol 57:111-118

Wolosker H, Panizzutti R, de Miranda J (2002) Neurobiology through the looking-glass: D-serine as a new glial-derived transmitter. Neurochem Int 41:327-332

Wu S, Barger SW, Sims TJ (2004) Schwann cell and epineural fibroblast expression of serine racemase. Brain Res 1020:161166 